\title{
Vaccination and Atherosclerosis
}

\author{
Xinghua Zhou, MD, PhD, and Göran K. Hansson, MD, PhD
}

\author{
Address \\ Center for Molecular Medicine L8:03, Karolinska Hospital, \\ Karolinska Institutet, S-17I76 Stockholm, Sweden. \\ E-mail: Xinghua.Zhou@cmm.ki.se \\ Current Atherosclerosis Reports 2004, 6: 158-164 \\ Current Science Inc. ISSN I523-3804 \\ Copyright $(2004$ by Current Science Inc.
}

Atherosclerosis is an inflammatory disease. Both innate and adaptive immunity are involved in lesion formation and development. A number of antigen candidates, such as oxidized low-density lipoprotein and heat shock protein, have been associated with the inflammation and immune reaction that is part of the atherosclerotic process.

Because experimental models of some other inflammatory/ autoimmune diseases can be improved by vaccination, it is of interest to investigate if vaccination can also be applied to prevent or retard atherosclerosis. Indeed, the modification of immune responses in animal models can greatly affect the development and progression of atherosclerosis. This review provides an overview of our current understanding of effects and proposed mechanisms of immunization on preventing atherosclerosis.

\section{Introduction}

Vaccination originally referred to a phenomenon in which the infection with a bovine analogue of smallpox, vaccinia, stimulated an immune response that cross-reacts with smallpox and thereby conferred protection from the human form of the disease. The term has been further extended to the induction of immunoprotection to other infectious agents. Vaccination has been a very effective way of controlling infectious diseases over the past 200 years, virtually eliminating several human lethal diseases such as diphtheria, polio, and measles in the Western world.

Atherosclerosis is characterized by patchy subintimal thickenings of medium and large arteries, which reduce or obstruct blood flow and lead to myocardial infarction, cerebral infarction, aortic aneurysm, and peripheral vascular diseases. As a consequence, atherosclerosis remains the principal cause of death in the Western world and much of Asia. In recent years, the pathogenesis of atherosclerosis has been revealed to be related not only to cholesterol deposition, macrophage infiltration, and smooth muscle cell (SMC) proliferation in the lesions, but also systemic and local innate and adaptive immune responses $[1 \bullet \bullet, 2 \bullet \bullet]$.
The first line of immune defense is dependent on detection of pathogen-associated molecular patterns (PAMPs), which evoke an inflammatory response. These PAMPs include endotoxin/lipopolysaccharides (LPS), lipoteichoic acid, heat shock proteins (HSPs), peptide glycans, and prokaryotic DNA motifs, which can all be recognized by the scavenger and Toll-like receptors on macrophages. Such a ligation leads to endocytosis and lysosomal degradation of the PAMP-coated particles and activates nuclear factor $\mathrm{KB}$ (NF-KB) signaling pathway in phagocytes [3]. Importantly, pattern recognition receptors, including scavenger receptors (SRs) and probably also Toll-like receptors (TLRs), bind oxidatively modified low-density lipoprotein (LDL) particles [4-6]. LDL modification, therefore, generates PAMP and elicits innate immune responses. Studies have further indicated that the initiation of atherosclerosis can be viewed as a response of the innate immune system to the accumulation and modification of lipoprotein in the intima. Indeed, lack of scavenger receptor A (SR-A) or CD36 through geneknockout technique in vivo decreases the development of atherosclerosis in murine models $[7,8]$.

$\mathrm{T}$ cells, which are key representatives of adaptive immunity, also participate in the formation of atherosclerosis as early as monocytes and macrophages [ $9 \bullet]$. Atherosclerotic lesions contain significant amounts of activated T cells, with the expression of T-cell cytokines such as interferon $\gamma$ (IFN $\gamma$ ) and of cytokine-induced genes like HLA-DR in the lesions $[10,11]$. The expression of HLA-DR by activated macrophages and activated $T$ cells adjacent to these macrophages in the lesions strongly suggests that a cellmediated immune reaction is taking place in the process of atherosclerosis. Lack of IFN $\gamma$ or its receptor as well as complete lack of adaptive immunity in murine models leads to less lesion formation [12-15], whereas T-cell transfer or direct IFN $\gamma$ injection exaggerates atherosclerosis $[13,16]$.

Although a minority of lymphocytes in human plaques bears markers for B cells, mRNA expression of $\kappa$-chain was detected in the lesions of animal model [17]. High-titer autoantibodies, produced by activated B cells and specific to oxidized (ox) LDL, have been found in circulation and lesions of humans and hypercholesterolemic animal models $[18,19]$. Furthermore, complement factors such as $\mathrm{C} 1$ and C3b, terminal C5b-9 complement complex, and complement receptors have also been found in human and animal lesions. These findings suggest that activation of humoral immune responses is also involved in the disease process $[20,21]$. The findings that removal of B cells via splectomy enhances lesion formation whereas polyclonal 
intravenous immunoglobulin ( $\mathrm{IVIg}$ ) injection suppresses the disease are in agreement with this hypothesis $[22,23 \bullet]$.

It has been shown in animal models that some inflammatory and autoimmune diseases such as rheumatoid arthritis and multiple sclerosis could be attacked by means of vaccination $[24,25]$. It is, therefore, of particular interest to explore if vaccination can be introduced to prevent or retard atherosclerosis, given the results that the manipulation of immune response in animals can greatly affect the development and progression of atherosclerosis [12,13,26-29]. Indeed, studies on this issue have provided promising data over the past few years. This review discusses several potential antigens that have been found to be involved in the development of atherosclerosis, with specific focus on the effect and proposed mechanism(s) of immunization.

\section{Antigens and Immunization in Atherosclerosis Oxidized low-density lipoprotein}

An increased level of serum cholesterol, especially LDL cholesterol, is a well-known risk factor for atherosclerosis [6]. LDL can be oxidized in the intima of the artery wall; this may be mediated by endothelial cells (EC), SMCs, and macrophages via several pathways, including those involving superoxide anion, ceruloplasmin, and lipoxygenase. OxLDL, one of the most important autoantigens, is, therefore, present in atherosclerotic lesions [30]. Macrophages can present neoantigens such as oxLDL to induce a T-cell-dependent immune response [31]. Indeed, SR-mediated uptake of oxLDL can lead to processing and presentation of particle fragments as major histocompatibility complex (MHC) class II bound antigens [31]. This process elicits a CD4+ T-cell response. As a matter of fact, $10 \%$ of CD4+ T cells cloned from human lesions recognized oxLDL [32]. It is likely that many of these $T$ cells were activated by oxLDL presented in regional lymph nodes, but direct antigen presentation in the plaque remains an additional important mechanism for activation of oxLDL-specific CD4+ T cells.

High-titer autoantibodies, produced by activated B cells and specific to oxLDL, have been found in blood and lesions of humans and hypercholesterolemic animal models $[18,19,33]$. The titer of autoantibodies to epitopes of oxLDL has been correlated with the extent of atherosclerosis in humans and murine models [18]. However, another study failed to show such a correlation in humans [34].

Apart from eliciting adaptive immunity, intimal oxLDL activates macrophages and ECs to express adhesion molecules, recruits immune cells and SMCs to the arterial intima, transforms macrophages into foam cells, impairs nitric oxide activity, induces complement activation, and impacts on coagulation and thrombosis [35-38]. OxLDL also induces secretion by macrophages, SMCs, and antigen-specific T cells of tumor necrosis factor $\alpha($ TNF- $\alpha$ ), interleukin (IL)-1, -8, -12, -15, and IFN $\gamma$; all of these cytokines may contribute to the development of atherosclerosis [32,39-42]. High concentrations of oxLDL exhibit cyto- toxic effects on ECs and SMCs, suggesting that they may cause endothelial dysfunction and promote fatty streak evolution [43].

Immunization with oxLDL ameliorates atherosclerosis in several animal models $[44,45]$. This effect is associated with increased titer of IgG anti-oxLDL (ie, T-cell- dependent B cell response) [45] and may, therefore, involve T-cell as well as B cell activation. Immunization with oxLDL also leads to a reduction of neointimal formation after balloon injury [46]. Such protective effects might involve Fc-dependent removal of oxLDL from the circulation or neutralizing the effects of oxLDL systemically or locally. It may also relate to the activation of cellular immune responses [45].

As LDL is a complex lipoprotein particle with molecular weight of approximately $2000 \mathrm{kD}$, it is necessary to define the antigenic epitopes in order to pursue vaccine development. In recent study, immunizing mice with human apolipoprotein (apo)B100 peptides led to a reduction in lesion size [47•]. Two groups of peptide mixture were chosen. The first group consisted of two peptides of the human apoB 100 with $85 \%$ to $90 \%$ homology to mice, whereas the second mixture contained five peptides, three of which were completely nonhomologous to mice. In the first immunization group, there was an approximately $60 \%$ decrease in lesion size accompanied by increased collagen in plaques and elevated titers of IgG antibodies against oxLDL in the circulation. However, the other group did not show any protective effect on the development of atherosclerosis [ $47 \bullet]$. Protein sequence, therefore, appears to play a crucial role for the immunoprotective effect.

It seems conflicting that immunization-induced humoral immune response to oxLDL is protective [44,45], whereas high titer of autoantibodies against oxLDL is correlated with the extent of atherosclerosis [18]. Such a contradiction may be explained by a hypothesis that there are two different types of antibodies produced in vivo. One is a "protective" antibody induced by immunization and related to the clearance of oxLDL cholesterol from circulation, whereas the other is a "pathogenic" autoantibody involved in the deposition of cholesterol in the arterial wall [48]. Alternatively, antibodies may reflect immunization, but neither play any important pathogenetic role nor protect from the disease. If this is the case, cellular immune responses may be decisive. Immunization experiments in immunodeficient mice should shed light on these possibilities.

\section{Heat shock protein}

Heat shock proteins, another group of proposed atherosclerosis-related antigens, may also contribute to autoimmunity in the disease [49•]. HSPs, which are expressed ubiquitously and constitutively and function to stabilize and protect newly synthesized proteins during folding, are released by injured cells and by monocytes exposed to oxLDL [50]. HSPs can serve as targets for autoimmune responses in many inflammatory diseases such as Crohn's disease and rheumatoid arthritis. HSPs display striking homologies throughout 
evolution, with significant sequence similarity between mammalian HSP60, chlamydial HSP60, and mycobacterial HSP65 [51]. It is, therefore, possible that some immune reactions to HSPs reflect molecular mimicry between microbial and human antigens [49•]. Several types of HSPs have been found in atherosclerotic lesions [52,53]. The titer of antibody to HSP65 appears to correlate with the progression of atherosclerosis [54]. Circulating antibodies to HSP65 in patients with atherosclerosis may reflect an autoimmune reaction to injured endothelium, which expresses high levels of HSP65. It is likely that this autoimmune response is not the primary event in atherosclerosis but secondary to an initial assault. An alternative and equally possible explanation could be that these antibodies may initially bind to HSPs on invading microbes and then cross-react with their human homologue HSP60, which may account for the association between infections and atherosclerosis [51].

Immunization with HSP60 has been reported to aggravate fatty streak lesion formation in atherosclerotic rabbit and mouse models $[53,55]$. Such an immunization induces vascular inflammation with infiltrates of HSP-reactive T cells [53]. The mechanisms involve both cellular and humoral immune reactions because adoptive transfer of HSP-specific lymph node cells or repeated intraperitoneal administration of IgG from serum of HSP-immunized mice promotes fatty streak formation [56]. Interestingly, HSP60, like bacterial endotoxin, can also activate Toll-like receptor 4 on mononuclear cells in a CD14-dependent manner [57], which suggests that HSPs not only induce adaptive immune responses but activate innate immunity as well.

Interestingly, a recent study shows an atheroprotective effect of HSP by mucosal immunization [58•]. Maron et al. [58•] applied nasal administration of HSP-65 on LDL-receptor knockout (LDLR KO) mice, and found that such a treatment significantly attenuated atherosclerotic lesion formation and T-cell infiltration accompanied by elevation of IL-10 expression in the lesions and of Th2-driven IgG1 anti-HSP antibodies in blood. The mechanisms of this atheroprotection may involve specific immune tolerance formation due to suppression of proinflammatory Th1-type immune response and induction of IL-4-secreting Th2 cell formation, as well as enhancement of anti-inflammatory cytokine IL-10/transforming growth factor- $\beta$ expression. Such effects are known to develop in response to mucosal immunization $[58 \bullet, 59]$.

\section{Microbial antigens}

Seroepidemiologic studies during the past 15 years show an association between cardiovascular diseases and microbial infections with certain bacteria as well as viruses of the herpes family. Chlamydia pneumoniae has been considered to be the most common microbe associated with cardiovascular diseases. Patients with acute myocardial infarction have high titers of antibodies against C. pneumoniae [60]. Interestingly, C. pneumoniae can be found in atherosclerotic plaques [61]. One study has reported a significant relationship between the abundance of $C$. pneumoniae and the severity of atherosclerotic disease [62], but others failed to detect a similar association $[63,64]$.

In animal studies, rabbits infected with C. pneumoniae display increased vascular inflammation and may also develop larger atherosclerotic lesions [65]. However, findings are contradictory in murine models. Some investigators report that infection of mice with C. pneumoniae accelerates atherosclerosis [66], whereas others could not detect any such correlation $[67,68]$. Therefore, the relationship between infection with $C$. pneumoniae and disease development needs to be further clarified.

Infection with C. pneumoniae might affect atherosclerosis by secreting LPS to induce acute inflammation with Creactive protein elevation, or by releasing HSP60 to cause a chronic reaction that induces autoimmunity against vascular cells. Some studies suggest that antibiotic treatment can attenuate disease progression concomitant with increased titers of antibodies to C. pneumoniae [69,70]. However, the Weekly Intervention with Zithromax for Atherosclerosis and Its Related Disorders (WIZARD) study [71•], the largest trial of antibiotic therapy for coronary artery disease, did not detect any beneficial effect of azithromycin on myocardial infarction. This argues against C. pneumoniae as a cause of coronary heart disease [71•].

Phosphorylcholine, one of the structural components of bacteria, is also present in oxLDL [72]. Some autoantibodies reactive against oxLDL cross-react with phosphorylcholine and protect against common pneumococcal infections [33,73]. Recently, Binder et al. [74••] showed that immunization of LDLR KO mice with Streptococcus pneumoniae dramatically reduced lesion development in parallel with elevation of oxLDL-specific IgM antibodies that cross-react with pneumococcal epitopes. This study suggests a new potential vaccination-based strategy for ameliorating atherosclerosis.

The herpes group viruses, including cytomegalovirus (CMV) and herpes simplex virus type I (HSV-I), have been associated with atherosclerosis [75]. Both CMV and HSV are found in atherosclerotic lesions. $\mathrm{CMV}$ is also linked to transplant arteriosclerosis and restenosis after coronary atherectomy $[76,77]$. Infection of apoE knockout (apoE KO) mice with murine $\gamma$-herpes viruses and CMV aggravates atherosclerosis $[78,79]$. The role for these viruses in disease progression may be due to their effects on smooth muscle cell migration [80].

Another virus, influenza, has also been suggested to cause increased cardiovascular disease and to trigger myocardial infarction $[81,82]$. Vaccination against influenza in humans is associated with reduced risk of recurrent myocardial infarction [83]. Recently, Naghavi et al. [84] have reported that infection of apoE $\mathrm{KO}$ mice with influenza $\mathrm{A}$ virus significantly increases atherosclerosis, suggesting that influenza A virus may have proatherogenic effects.

However, the fact that atherosclerosis in germ-free apoE $\mathrm{KO}$ mice is not different from that in apoE $\mathrm{KO}$ mice raised with ambient levels of microbial challenge suggests that 
infectious agents are not necessary for atherosclerosis [85]. Instead, they may play an important accelerating role in the disease progression.

\section{Beta 2-glycoprotein and others}

The $\beta 2$-glycoprotein I ( $\beta 2$-GPI) is present on platelets and on the surface of ECs. Autoantibodies against $\beta 2$-GPI are associated with prothrombotic effects and produced in patients with antiphospholipid syndrome as well as other inflammatory diseases, including atherosclerosis. $\beta 2$-GPI is also found in the subendothelial regions and the intima of human atherosclerotic plaques [86]. High titers of anti- $\beta 2$-GPI antibodies together with anti-oxLDL antibodies are observed in the patients with coronary artery disease [87]. Immunization of LDLR KO mice with human $\beta 2$-GPI remarkably accelerates atherosclerosis [88]. Such a proatherogenic effect of anti- $\beta 2$-GPI immunity may be due to the fact that anti- $\beta 2$-GPI antibodies can activate ECs [88] and enhance the uptake of oxLDL by macrophages [89].

Another glycoprotein related to atherosclerosis is cholesteryl ester transfer protein (CETP), which is secreted from the liver and bound mainly to high-density lipoprotein (HDL). The function of CETP is to transfer cholesteryl esters from HDL to LDL and very low-density lipoprotein (VLDL). The effect of CETP on atherosclerosis is controversial; it is either antiatherogenic when CETP increases the rate of reverse cholesterol transport from peripheral tissues to the liver for elimination, or proatherogenic when CETP redistributes cholesteryl esters from HDL to LDL/VLDL and/or decreases the HDL concentration in peripheral tissues [90]. Mice transgenic with either human apoC-III or human lecithin-cholesteryl acyltransferase exhibit increased atherosclerosis [91,92], whereas introduction of CETP into these mice ameliorates the disease $[91,93]$. However, overexpression of CETP in apoE KO mice and LDLR KO mice accelerates atherosclerosis [94]. Rittershaus et al. [95] have recently reported that immunization of cholesterol-fed rabbits with CETP attenuates disease progression accompanied by increased levels of HDL cholesterol. The mechanism of such an atheroprotection may be a suppression of CETP activity by vaccination-induced antibodies.

The role of platelet-derived growth factor (PDGF) in atherosclerosis has also been tested by vaccination. PDGF is an important growth factor that may mediate migration and proliferation of SMCs in the intima [43]. It can be secreted by dysfunctional ECs, monophages, and macrophages, as well as by SMCs in lesions. Immunization of cholesterol-fed rabbits with recombinant human PDGF significantly reduces lesion formation in parallel with raised antibodies against PDGF [96]. Such a protection may be due to the specific antibodies neutralizing atherosclerotic effects of PDGF [96].

\section{Conclusions}

Many studies suggest that modification of the immune response could affect the process of atherosclerosis, given the evidence that vaccination with certain antigens attenuates the disease. The results from immunization of animals with oxLDL or certain peptide sequences derived from oxLDL are encouraging for the future development of a vaccination approach in atherosclerosis prevention and treatment. Although the microbial theory in the pathogenesis of atherosclerosis remains unproved, mucosal HSP vaccination may provide a new immunologic insight into the treatment of the disease. The antiphosphorylcholine studies have opened a new window to the molecular mimicry between certain bacterial infection and LDL oxidation. It will, therefore, be interesting to see if transfer of such an antiphosphorylcholine specific antibody can protect from atherosclerosis.

It is clear that much work will be required to locate the precise molecular epitopes of the atherosclerosis-related antigens and to clarify the mechanism involved in atheroprotection achieved by immunization. At present, we are still far from a clinical application in patients with atherosclerosis and its associated complications. However, recent results obtained in experimental models encourage further research in this field.

\section{Acknowledgment}

This work was supported by the Swedish Research Council (projects no 14245 and 6816), Swedish Heart Lung Foundation, AFA, Söderberg Foundation, Gun och Bertil Stohnes Foundation, Loo och Hans Ostermans Foundation, Gamla Tjänarinnor Foundation, and Nanna Swartz Foundation. Dr. Zhou is the recipient of a career investigator award from the Swedish Research Council.

\section{References and Recommended Reading}

Papers of particular interest, published recently,

have been highlighted as:

- Of importance

-• Of major importance

1.• Binder CJ, Chang MK, Shaw PX, et al.: Innate and acquired immunity in atherogenesis. Nat Med 2002, 8:1218-1226.

An excellent review on current understanding of pathogenesis of atherosclerosis

2.• Hansson GK, Libby $\mathrm{P}$, Schonbeck U, et al.: Innate and adaptive immunity in the pathogenesis of atherosclerosis. Circ Res 2002, 91:281-291.

A comprehensive review on the role of innate and acquired immunity in the development of atherosclerosis.

3. Aliprantis AO, Yang RB, Mark MR, et al.: Cell activation and apoptosis by bacterial lipoproteins through toll-like receptor-2. Science 1999, 285:736-739.

4. Griffith RL, Virella GT, Stevenson HC, et al.: Low density lipoprotein metabolism by human macrophages activated with low density lipoprotein immune complexes. A possible mechanism of foam cell formation. J Exp Med 1988, 168:1041-1059. 
5. $\mathrm{Xu} \mathrm{XH}$, Shah $\mathrm{PK}$, Faure E, et al.: Toll-like receptor-4 is expressed by macrophages in murine and human lipid-rich atherosclerotic plaques and upregulated by oxidized LDL. Circulation 2001, 104:3103-3108.

6. Brown MS, Goldstein JL: A receptor-mediated pathway for cholesterol homeostasis. Science 1986, 232:34-47.

7. Suzuki $\mathrm{H}$, Kurihara $\mathrm{Y}$, Takeya $\mathrm{M}$, et al.: A role for macrophage scavenger receptors in atherosclerosis and susceptibility to infection. Nature 1997, 386:292-296.

8. Febbraio M, Podrez EA, Smith JD, et al.: Targeted disruption of the class $\mathrm{B}$ scavenger receptor $\mathrm{CD} 36$ protects against atherosclerotic lesion development in mice. J Clin Invest 2000, 105:1049-1056.

9. Zhou X: CD4+ T cells in atherosclerosis. Biomed Pharmacother 2003, 57:287-291.

A concise review specifically focused on the role of CD4+ T-cell subpopulations in atherosclerosis.

10. Jonasson L, Holm J, Skalli O, et al.: Expression of class II transplantation antigen on vascular smooth muscle cells in human atherosclerosis. J Clin Invest 1985, 76:125-131.

11. Hansson GK, Holm J, Jonasson L: Detection of activated T lymphocytes in the human atherosclerotic plaque. Am J Pathol 1989, 135:169-175.

12. Gupta S, Pablo AM, Jiang XC, et al.: IFN-gamma potentiates atherosclerosis in ApoE knock-out mice. J Clin Invest 1997, 99:2752-2761.

13. Zhou X, Nicoletti A, Elhage R, et al.: Transfer of CD4(+) T cells aggravates atherosclerosis in immunodeficient apolipoprotein E knockout mice. Circulation 2000, 102:2919-2922.

14. Song L, Leung C, Schindler C: Lymphocytes are important in early atherosclerosis. J Clin Invest 2001, 108:251-259.

15. Buono C, Come CE, Stavrakis G, et al.: Influence of interferongamma on the extent and phenotype of diet-induced atherosclerosis in the LDLR-deficient mouse. Arterioscler Thromb Vasc Biol 2003, 23:454-460.

16. Whitman SC, Ravisankar P, Elam H, et al:: Exogenous interferon-gamma enhances atherosclerosis in apolipoprotein E-/- mice. Am J Pathol 2000, 157:1819-1824.

17. Sohma Y, Sasano H, Shiga $R$, et al.: Accumulation of plasma cells in atherosclerotic lesions of Watanabe heritable hyperlipidemic rabbits. Proc Natl Acad Sci U S A 1995, 92:4937-4941.

18. Salonen JT, Yla-Herttuala S, Yamamoto R, et al: : Autoantibody against oxidised LDL and progression of carotid atherosclerosis. Lancet 1992, 339:883-887.

19. Ylä-Herttuala S, Palinski W, Butler SW, et al.: Rabbit and human atherosclerotic lesions contain IgG that recognizes epitopes of oxidized LDL. Arterioscler Thromb 1994, 14:32-40.

20. Seifert PS, Hansson GK: Decay-accelerating factor is expressed on vascular smooth muscle cells in human atherosclerotic lesions. J Clin Invest 1989, 84:597-604.

21. Seifert PS, Hugo F, Tranum-Jensen J, et al.: Isolation and characterization of a complement-activating lipid extracted from human atherosclerotic lesions. J Exp Med 1990, 172:547-557.

22. Nicoletti A, Kaveri S, Caligiuri G, et al.: Immunoglobulin treatment reduces atherosclerosis in apo $\mathrm{E}$ knockout mice. J Clin Invest 1998, 102:910-918.

23. Caligiuri G, Nicoletti A, Poirier B, et al.: Protective immunity against atherosclerosis carried by $B$ cells of hypercholesterolemic mice. I Clin Invest 2002, 109:745-753.

This study demonstrates for the first time that B cell-associated protective immunity develops during atherosclerosis and reduces disease progression in apoE knockout mice.

24. Backlund J, Treschow A, Bockermann R, et al.: Glycosylation of type II collagen is of major importance for $\mathrm{T}$ cell tolerance and pathology in collagen-induced arthritis. Eur J Immunol 2002, 32:3776-3784

25. Weiner HL, Selkoe DJ: Inflammation and therapeutic vaccination in CNS diseases. Nature 2002, 420:879-884.

26. Mallat Z, Besnard S, Duriez M, et al.: Protective role of interleukin-10 in atherosclerosis. Circ Res 1999, 85:e17-e24.
27. Smith JD, Trogan E, Ginsberg M, et al.: Decreased atherosclerosis in mice deficient in both macrophage colony-stimulating factor (op) and apolipoprotein E. Proc Natl Acad Sci U S A 1995, 92:8264-8268.

28. Elhage R, Maret A, Pieraggi MT, et al.: Differential effects of interleukin-1 receptor antagonist and tumor necrosis factor binding protein on fatty-streak formation in apolipoprotein E-deficient mice. Circulation 1998, 97:242-244.

29. Mach F, Schonbeck U, Sukhova GK, et al.: Reduction of atherosclerosis in mice by inhibition of CD40 signalling. Nature 1998, 394:200-203.

30. Palinski W, Rosenfeld ME, Yla HS, et al.: Low density lipoprotein undergoes oxidative modification in vivo. Proc Natl Acad Sci U S A 1989, 86:1372-1376.

31. Nicoletti A, Caligiuri G, Tornberg I, et al:: The macrophage scavenger receptor type A directs modified proteins to antigen presentation. Eur J Immunol 1999, 29:512-521.

32. Stemme S, Faber B, Holm J, et al.: T lymphocytes from human atherosclerotic plaques recognize oxidized low density lipoprotein. Proc Natl Acad Sci U S A 1995, 92:3893-3897.

33. Palinski W, Horkko $S$, Miller E, et al.: Cloning of monoclonal autoantibodies to epitopes of oxidized lipoproteins from apolipoprotein E-deficient mice. Demonstration of epitopes of oxidized low density lipoprotein in human plasma. J Clin Invest 1996, 98:800-814

34. Schumacher M, Eber B, Tatzber F, et al.: LDL oxidation and coronary atherosclerosis [letter; comment]. Lancet 1992, 340:123.

35. Seifert PS, Kazatchkine MD: Generation of complement anaphylatoxins and C5b-9 by crystalline cholesterol oxidation derivatives depends on hydroxyl group number and position. Mol Immunol 1987, 24:1303-1308.

36. Latron $Y$, Chautan M, Anfosso F, et al.: Stimulating effect of oxidized low density lipoproteins on plasminogen activator inhibitor-1 synthesis by endothelial cells. Arterioscler Thromb 1991, 11:1821-1829.

37. Kume N, Cybulsky MI, Gimbrone MJ: Lysophosphatidylcholine, a component of atherogenic lipoproteins, induces mononuclear leukocyte adhesion molecules in cultured human and rabbit arterial endothelial cells. J Clin Invest 1992, 90:1138-1144.

38. Muller K, Hardwick SJ, Marchant CE, et al.: Cytotoxic and chemotactic potencies of several aldehydic components of oxidised low density lipoprotein for human monocytemacrophages. FEBS Lett 1996, 388:165-168.

39. Terkeltaub R, Banka CL, Solan J, et al.: Oxidized LDL induces monocytic cell expression of interleukin-8, a chemokine with T-lymphocyte chemotactic activity. Arterioscler Thromb Vasc Biol1994, 14:47-53.

40. Jovinge $\mathrm{S}$, Ares MP, Kallin B, et al.: Human monocytes/ macrophages release TNF-alpha in response to Ox-LDL. Arterioscler Thromb Vasc Biol 1996, 16:1573-1579.

41. Uyemura K, Demer LL, Castle SC, et al:: Cross-regulatory roles of interleukin (IL)-12 and IL-10 in atherosclerosis. J Clin Invest $1996,97: 2130-2138$.

42. Wuttge DM, Eriksson P, Sirsjo A, et al: : Expression of interleukin-15 in mouse and human atherosclerotic lesions. Am J Pathol 2001, 159:417-423.

43. Ross R: Atherosclerosis-an inflammatory disease. N Engl J Med 1999, 340:115-126.

44. Palinski W, Miller E, Witztum JL: Immunization of low density lipoprotein (LDL) receptor-deficient rabbits with homologous malondialdehyde-modified LDL reduces atherogenesis. Proc Natl Acad Sci U S A 1995, 92:821-825.

45. Zhou X, Caligiuri G, Hamsten A, et al.: LDL immunization induces $\mathrm{T}$-cell-dependent antibody formation and protection against atherosclerosis. Arterioscler Thromb Vasc Biol 2001, 21:108-114.

46. Nilsson J, Calara F, Regnström J, et al.: Immunization with homologous oxidized low density lipoprotein reduces neointimal formation after balloon injury in hypercholesterolemic rabbits. J Am Coll Cardiol 1997, 30:1886-1891. 
47. Nordin-Fredrikson G, Soderberg I, Lindholm M, et al: Inhibition of atherosclerosis in apoE-null mice by immunization with apoB-100 peptide sequences. Arterioscler Thromb Vasc Biol 2003, 23:879-884.

This study shows in a murine model that certain peptide sequences of apoB-100 can inhibit atherosclerosis, which may be useful in the development of a vaccine strategy.

48. Sherer Y, Shoenfeld Y: Immunomodulation for treatment and prevention of atherosclerosis. Autoimmun Rev 2002, 1:21-27.

49. Wick G: Atherosclerosis-an autoimmune disease due to an immune reaction against heat-shock protein 60 . Herz 2000, 25:87-90.

A comprehensive review specifically focused on the relationship between HSP and atherosclerosis.

50. Frostegård J, Kjellman B, Gidlund M, et al.: Induction of heat shock protein in monocytic cells by oxidized low density lipoprotein. Atherosclerosis 1996, 121:93-103.

51. Mayr M, Metzler B, Kiechl S, et al.: Endothelial cytotoxicity mediated by serum antibodies to heat shock proteins of Escherichia coli and Chlamydia pneumoniae: immune reactions to heat shock proteins as a possible link between infection and atherosclerosis. Circulation 1999, 99:1560-1566.

52. Berberian PA, Myers W, Tytell M, et al.: Immunohistochemical localization of heat shock protein-70 in normal- appearing and atherosclerotic specimens of human arteries. Am J Pathol 1990, 136:71-80.

53. Xu Q, Kleindienst R, Waitz W, et al.: Increased expression of heat shock protein 65 coincides with a population of infiltrating $T$ lymphocytes in atherosclerotic lesions of rabbits specifically responding to heat shock protein 65 . J Clin Invest 1993, 91:2693-2702.

54. Xu Q, Kiechl S, Mayr M, et al:: Association of serum antibodies to heat-shock protein 65 with carotid atherosclerosis: clinical significance determined in a follow-up study [see comments]. Circulation 1999, 100:1169-1174.

55. George J, Shoenfeld Y, Afek A, et al.: Enhanced fatty streak formation in C57BL/6J mice by immunization with heat shock protein-65. Arterioscler Thromb Vasc Biol 1999, 19:505-510.

56. George J, Afek A, Gilburd B, et al.: Cellular and humoral immune responses to heat shock protein 65 are both involved in promoting fatty-streak formation in LDLreceptor deficient mice. J Am Coll Cardiol 2001, 38:900-905.

57. Kol A, Lichtman AH, Finberg RW, et al.: Cutting edge: heat shock protein (HSP) 60 activates the innate immune response: CD14 is an essential receptor for HSP60 activation of mononuclear cells. J Immunol 2000, 164:13-17.

58. Maron R, Sukhova G, Faria AM, et al.: Mucosal administration of heat shock protein- 65 decreases atherosclerosis and inflammation in aortic arch of low-density lipoprotein receptor-deficient mice. Circulation 2002, 106:1708-1715.

This study demonstrates by nasal administration of HSP that mucosal vaccination can reduce atherosclerosis formation in a murine model.

59. Faria AM, Weiner HL: Oral tolerance: mechanisms and therapeutic applications. Adv Immunol 1999, 73:153-264.

60. Saikku P, Leinonen M, Mattila K, et al.: Serological evidence of an association of a novel Chlamydia, TWAR, with chronic coronary heart disease and acute myocardial infarction. Lancet 1988, 2:983-986.

61. Kuo CC, Gown AM, Benditt EP, et al.: Detection of Chlamydia pneumoniae in aortic lesions of atherosclerosis by immunocytochemical stain. Arterioscler Thromb 1993, 13:1501-1504.

62. Vink A, Poppen M, Schoneveld AH, et al.: Distribution of Chlamydia pneumoniae in the human arterial system and its relation to the local amount of atherosclerosis within the individual. Circulation 2001, 103:1613-1617.

63. Thomas M, Wong $\mathrm{Y}$, Thomas $\mathrm{D}$, et al.: Relation between direct detection of Chlamydia pneumoniae DNA in human coronary arteries at postmortem examination and histological severity (Stary grading) of associated atherosclerotic plaque. Circulation 1999, 99:2733-2736.
64. Danesh J, Whincup P, Walker M, et al:: Chlamydia pneumoniae IgG titres and coronary heart disease: prospective study and meta-analysis. BMJ 2000, 321:208-213.

65. Fong IW, Chiu B, Viira E, et al.: De novo induction of atherosclerosis by Chlamydia pneumoniae in a rabbit model. Infect Immun 1999, 67:6048-6055.

66. Moazed TC, Campbell LA, Rosenfeld ME, et al:: Chlamydia pneumoniae infection accelerates the progression of atherosclerosis in apolipoprotein E-deficient mice. J Infect Dis 1999, 180:238-241.

67. Caligiuri G, Rottenberg M, Nicoletti A, et al.: Chlamydia pneumoniae infection does not induce or modify atherosclerosis in mice. Circulation 2001, 103:2834-2838.

68. Aalto-Setala K, Laitinen K, Erkkila L, et al.: Chlamydia pneumoniae does not increase atherosclerosis in the aortic root of apolipoprotein E-deficient mice. Arterioscler Thromb Vasc Biol 2001, 21:578-584.

69. Gupta S, Leatham EW, Carrington D, et al.: Elevated Chlamydia pneumoniae antibodies, cardiovascular events, and azithromycin in male survivors of myocardial infarction. Circulation 1997, 96:404-407.

70. Gurfinkel E, Bozovich G, Daroca A, et al.: Randomised trial of roxithromycin in non-Q-wave coronary syndromes: ROXIS Pilot Study. ROXIS Study Group. Lancet 1997, 350:404-407.

71. O'Connor CM, Dunne MW, Pfeffer MA, et al.: Azithromycin for the second prevention of coronary heart disease events. The WIZARD study: a randomized controlled trial. JAMA 2003, 290:1459-1466.

This large trial reports that there is no beneficial effect of the antibiotic azithromycin on myocardial infarction, which argues against Chlamydia pneumoniae as a cause of coronary heart disease.

72. Hörkkö S, Bird DA, Miller E, et al.: Monoclonal autoantibodies specific for oxidized phospholipids or oxidized phospholipid-protein adducts inhibit macrophage uptake of oxidized low-density lipoproteins. J Clin Invest 1999, 103:117-128.

73. Shaw PX, Hörkkö S, Chang MK, et al.: Natural antibodies with the T15 idiotype may act in atherosclerosis, apoptotic clearance, and protective immunity. J Clin Invest 2000, 105:1731-1740

74.•• Binder CJ, Hörkkö S, Dewan A, et al.: Pneumococcal vaccination decreases atherosclerotic lesion formation: molecular mimicry between Streptococcus pneumoniae and oxidized LDL. Nat Med 2003, 9:736-743.

This interesting paper demonstrates a molecular mimicry between epitopes of oxLDL and Streptococcus pneumoniae, and indicates beneficial effects on atherosclerosis.

75. Epstein SE, Zhou YF, Zhu J: Infection and atherosclerosis: emerging mechanistic paradigms. Circulation 1999, 100:e20-e28.

76. McDonald K, Rector TS, Braulin EA, et al:: Association of coronary artery disease in cardiac transplant recipients with cytomegalovirus infection. Am J Cardiol 1989, 64:359-362.

77. Zhou YF, Leon MB, Waclawiw MA, et al.: Association between prior cytomegalovirus infection and the risk of restenosis after coronary atherectomy. N Engl J Med 1996, 335:624-630.

78. Alber DG, Powell KL, Vallance P, et al.: Herpesvirus infection accelerates atherosclerosis in the apolipoprotein E-deficient mouse. Circulation 2000, 102:779-785.

79. Hsich E, Zhou YF, Paigen B, et al.: Cytomegalovirus infection increases development of atherosclerosis in apolipoproteinE knockout mice. Atherosclerosis 2001, 156:23-28.

80. Streblow DN, Soderberg-Naucler C, Vieira J, et al.: The human cytomegalovirus chemokine receptor US28 mediates vascular smooth muscle cell migration. Cell 1999, 99:511-520.

81. Group TE: Cold exposure and winter mortality from ischaemic heart disease, cerebrovascular disease, respiratory disease, and all causes in warm and cold regions of Europe. The Eurowinter Group. Lancet 1997, 349:1341-1346.

82. Meier CR, Jick SS, Derby LE, et al.: Acute respiratory-tract infections and risk of first-time acute myocardial infarction. Lancet 1998, 351:1467-1471. 
83. Naghavi M, Barlas Z, Siadaty $S$, et al.: Association of influenza vaccination and reduced risk of recurrent myocardial infarction. Circulation 2000, 102:3039-3045.

84. Naghavi M, Wyde P, Litovsky S, et al.: Influenza infection exerts prominent inflammatory and thrombotic effects on the atherosclerotic plaques of apolipoprotein E-deficient mice. Circulation 2003, 107:762-768.

85. Wright SD, Burton C, Hernandez M, et al.: Infectious agents are not necessary for murine atherogenesis. J Exp Med 2000, 191:1437-1442.

86. George J, Harats D, Gilburd B, et al.: Immunolocalization of beta2-glycoprotein I (apolipoprotein $\mathrm{H}$ ) to human atherosclerotic plaques: potential implications for lesion progression. Circulation 1999, 99:2227-2230.

87. Sherer Y, Tenenbaum A, Praprotnik S, et al.: Coronary artery disease but not coronary calcification is associated with elevated levels of cardiolipin, beta-2-glycoprotein-I, and oxidized LDL antibodies. Cardiology 2001, 95:20-24.

88. George J, Afek A, Gilburd B, et al.: Induction of early atherosclerosis in LDL-receptor-deficient mice immunized with beta2-glycoprotein I. Circulation 1998, 98:1108-1115.

89. Hasunuma Y, Matsuura E, Makita Z, et al.: Involvement of beta 2-glycoprotein I and anticardiolipin antibodies in oxidatively modified low-density lipoprotein uptake by macrophages. Clin Exp Immunol 1997, 107:569-573.

90. Barter P: CETP and atherosclerosis. Arterioscler Thromb Vasc Biol 2000, 20:2029-2031.
91. Hayek T, Masucci-Magoulas L, Jiang X, et al.: Decreased early atherosclerotic lesions in hypertriglyceridemic mice expressing cholesteryl ester transfer protein transgene. J Clin Invest 1995, 96:2071-2074.

92. Berard AM, Foger B, Remaley A, et al.: High plasma HDL concentrations associated with enhanced atherosclerosis in transgenic mice overexpressing lecithin-cholesteryl acyltransferase. Nat Med 1997, 3:744-749.

93. Foger B, Chase M, Amar MJ, et al: : Cholesteryl ester transfer protein corrects dysfunctional high density lipoproteins and reduces aortic atherosclerosis in lecithin cholesterol acyltransferase transgenic mice. J Biol Chem 1999, 274:36912-36920.

94. Plump AS, Masucci-Magoulas L, Bruce C, et al.: Increased atherosclerosis in ApoE and LDL receptor gene knockout mice as a result of human cholesteryl ester transfer protein transgene expression. Arterioscler Thromb Vasc Biol 1999, 19:1105-1110.

95. Rittershaus CW, Miller DP, Thomas LJ, et al.: Vaccine-induced antibodies inhibit CETP activity in vivo and reduce aortic lesions in a rabbit model of atherosclerosis. Arterioscler Thromb Vasc Biol 2000, 20:2106-2112.

96. Lamb DJ, Avades TY, Ferns GA: Endogenous neutralizing antibodies against platelet-derived growth factor-aa inhibit atherogenesis in the cholesterol-fed rabbit. Arterioscler Thromb Vasc Biol 2001, 21:997-1003. 